Student musicians'self and task-theories of musical performance: the influence of primary genre affiliation 


\section{BIOGRAPHICAL NOTE}

Dr Allan Hewitt is Head of Department of Sport, Culture and the Arts at the University of Strathclyde, Glasgow. He teaches across a range of undergraduate music and music education programmes and is an active performer and composer. Research interests are in pedagogical aspects of instrumental learning, children's creativity, and the relationship between social factors, uptake and attainment in formal education.

\section{CONTACT INFORMATION}

Tom Bone Building

76 Southbrae Drive

Glasgow,

Scotland

G13 1PP

Email: allan.hewitt@sstrath.ac.uk

Telephone: 01419503476 


\begin{abstract}
165 undergraduate music students studying in Scotland completed a 30-statement Q-sort to describe their self and task-theories of musical performance. Statements reflected the importance of effort, confidence, technical ability, significant others and luck/ chance in determining a successful performance. The Q-sorts were reduced to six underlying sorting patterns, or viewpoints. The relationship between sorting patterns and participants' primary genre affiliation was explored in order to identify whether self and task-theories were a function of genre affiliation. Some intuitive hypotheses of what performers of particular musical genres might think were supported by the data. However, results suggested that there was considerable diversity in self and task-theory of performance within each of the genre affiliation groups, which supports previous research. Other background factors, such as gender, years of playing, chronological age and type of institution, were not significant predictors of self or task-theory of musical performance.
\end{abstract}

\title{
KEYWORDS
}

Music education, music performance, personality, undergraduate, genre affiliation, Q method 


\section{INTRODUCTION}

\section{Musical genres as communities of practice}

The purpose of this study was to identify how undergraduate music students view their capabilities as musicians and the activity of musical performance, and to explore how differences in these viewpoints may be related to their membership of different communities of practice defined by affiliation with a particular musical genre. The study identified the viewpoints of undergraduate music students affiliated with four different communities of practice (classical, jazz, pop/ rock and Scottish traditional). These are the main genres performed in public by undergraduate music students in Scotland and are the categories used by other researchers in this area (e.g. Creech, et al., 2008).

Engagement with the construct of musical genre immediately raises some important questions. How, in a musical sense, do we define a 'genre'? What differentiates one musical genre from another? Considerable research has taken place with the aim of objectively analysing and classifying music based on identifiable musical features that make one genre distinct from another; recent work has focussed almost exclusively on the development of automated computer models for stylistic identification (Cruz-Alcazar, Vidal-Ruiz, \& Perez-Cortes, 2003). Meyer (1989), for example, defined a 'genre' as a "replication of patterning...that results from a series of choices made within some set of constraints" (p.3). Importantly, these constraints are learned by those who work within a particular genre as players, composers and audience. Meyer argued that this learning is a product of a tacit understanding that develops over time, rather than through the vehicle of formal instruction.

In conjunction with the musical features that define a genre it is possible to identify a range of other normative aspects of practice and behaviour that distinguish one genre from another. Some of these 'genre-normative modes' (Stockfelt, 2004) are located within the audience; for example, there are marked differences in how the audience at a pop or rock concert engage in the activity of listening compared with the audience at a classical concert (Auslander, 2004). At a rock concert, the audience will feel quite free to sing along, clap, cheer, shout, issue requests and so on. At a classical concert, these same behaviours would probably result in rapid ejection. Some of these normative practices are venue-specific rather than genrespecific; audience participation at a traditional music 'session' is quite different from that experienced when the same music is transported to a venue more associated with classical music. The expectations of the audience may also be very different, depending on the genre of music. The audience at a jazz gig will probably expect to hear 'new' music, and will greatly appreciate expert improvisation. The audience at a classical concert would be quite startled if improvisation were to form any part of a rendition of a Beethoven symphony. These differences extend to the performers, in terms of dress, reaction to the audience, flexibility in programming, freedom to move around the stage, whether there are introductions to different 
items and so on. Important differences in how musical genres are transmitted, or taught, can also be readily identified (Cope, 2002).

Taking account of Meyer's earlier argument about learning within musical genres, it is tempting to consider each of these genres a 'community of practice', drawing on Lave and Wenger's theoretical framework (Lave \& Wenger, 1991). A community of practice can be defined on three dimensions; what it is about (a point that is continually renegotiated by the members of the community), how it functions (what are the features of the mutual engagement that create the social entity) and what capability it has produced (what are the routines, objects, vocabularies, practices that its members have developed over time). Crucially, membership of a community of practice does not happen automatically. As a socially constructed phenomenon (J. S. Brown, Collins, \& Duguid, 1989), group membership is generally characterised by an initial period on the periphery, and a growing level of engagement and identity as one demonstrates and understands (usually tacitly) the normative practices and modes of the community. For many educators, this is the true nature of 'learning'.

\section{Musical genres and undergraduate music education}

So how does this theoretical notion of communities of practice relate to music education at university and conservatoire level? If we suspect that different genres of music have their own set of normative practices, and if these are sometimes quite different from each other, we might reasonably expect to see variation in how young performers who affiliate most strongly with different genres conceptualise the activity of musical performance (i.e. their tasktheories). We may expect to see differences in the kinds of values they hold about performance, for example in the realm of technical expertise. We may expect different views on the influence and response of the audience within a performance, for example in the context of performer stress (LeBlanc, Jin, Obert, \& Siivola, 1997). In other words, there may be significant differences in attitude towards aspects of performance that are common across genres, and we might speculate that these differences will reflect important aspects of the community of practice into which the young musician is being, or indeed has been, initiated. In addition to differences in task-theory, we may also expect to find differences in young musicians' self-theories that are related to genre-related expertise. We may expect, for example, to find that musicians who perform predominantly classical music view themselves in terms of their capabilities and strengths in quite different ways to jazz or rock musicians. These intuitive hypotheses have formed the basis of emerging work in the area (e.g. Welch, et al., 2008)

Exploring and quantifying the extent of such differences in self and task-theories is of relevance from a pedagogical perspective. If a distinctive community of practice can be identified that represents the established normative practices of a particular musical genre, it follows that for a young musician to successfully enter that community they should exhibit (or inhabit) the behaviours and practices associated with the genre in which they wish to not only 
participate, but become 'expert'. Failure to do so may result in their being unable to participate, or being able to participate only in a restricted way. Educational programmes that aim to train young musicians in specific musical genres would be required to understand and embody salient aspects of those communities of practice, rather than simply adopting normative practices from other genres (Hargreaves \& Marshall, 2003). In addition, training processes may be more effective where unhelpful assumptions and practices that are implicitly accepted and which the student brings to the learning process, but which ultimately may hinder or restrict the young musician's development, are challenged and critiqued. Such provision requires a better understanding of the self and task-theories that underpin the communities of practice that relate to specific musical genres; this paper is an attempt to contribute to that understanding.

There is a limited amount of previous research with undergraduate student musicians that explores the relationship between genre affiliation and other aspects of learning. Most recently, a project team in the UK has published the findings of a study that examined these issues in some depth (Creech, et al., 2008; Welch, et al., 2008). Comparing students with a 'classical' affiliation to those with a 'non-classical' affiliation, they found some significant differences in self and task perception. For example, classical musicians were characterised by a stronger desire to excel musically and technically, compared with the non-classical musicians. This group also emphasised the importance of notation and aural skills. For nonclassical musicians the emphasis was on skills relating to memorisation and improvisation, which were not rated so important by the classical students. No significant differences were found between the two genre-affiliated groups in areas where they might have been expected, such as practising and instrumental lessons. The results presented in this paper confirm some of these findings and extend the analysis to capture the views of the 'non-classical' musicians in greater depth.

\section{The theoretical framework}

The study reported in this paper was based on participants' responses to a series of statements that referred to two different aspects of solo performance (see Appendix 1 for a list of the statements used). The first aspect covered by the statements was how the participant felt about themselves as performers; these can be considered the participants 'self-theories' (Dweck, 1999) about musical performance. A second aspect was what participants believed about the task of musical performance, their 'task-theories' in Dweck's terminology. The purpose of the study, therefore, was to identify the particular characteristics of each participant's self and task-theory in the context of musical performance, and then to relate this to other contextual factors such as primary genre affiliation, age, gender, years of learning their main instrument and type of institution they were attending.

The specific wording of the statements was based on work relating to a theory of Perceived Control (Schmitz \& Skinner, 1993; Skinner, 1995). This framework conceptualises the important perceptions about an activity (e.g. musical performance) as consisting of both what 
the individual thinks about their own competence in that activity specifically in terms of ability, effort, confidence, luck, and the role of others, and what they think is required to do well in that activity (again, in terms of ability, effort, confidence and so on). It is the disparity between what the individual thinks they can do and what they think they need to do (in other words, the disjunct between the self-theory and the task-theory) that is held to be the best predictor of ultimate achievement (Little, Lopez, Oettingen, \& Baltes, 2001). The statements used in this study therefore drew on the ideas of self and task-theory for an overall structure, and the specific aspects of self and task-theory that have been developed within the Perceived Control framework.

The 30 statements presented in Appendix 1 were considered to represent a concourse of views with which participants in the study would more or less strongly agree. As such, they represented a cohesive domain - a set of cultural tools, in Vygotskian terms (Vygotsky, 1986) about musical performance to which student performers with different primary genre affiliations were predicted to respond in significantly different ways. The remainder of this paper reports how participants responded to this concourse, how these responses were related to their primary genre affiliation and other factors, and what response patterns may reveal that is of importance to music educators.

\section{Methodology}

\section{Procedure}

The procedure used for data gathering and analysis was Q methodology. William Stephenson introduced $\mathrm{Q}$ as a method of investigating the subjective opinions, attitudes or beliefs of individual participants (Stephenson, 1953). It was useful in this study because it facilitates the statistical comparison of the views and rating patterns of different participants about a particular issue or context. Often the analysis is extended to include a factor analysis of underlying rating patterns in order to identify prototypical belief or attitudinal models shared by a subset of participants (S. R. Brown, 1980). The basic procedure in Q methodology is for the researcher to develop a set of items (often in the form of statements or phrases) that are drawn from the 'concourse' of ideas, concepts and so on related to the field of enquiry. Participants in the research study are then required to actively sort these items into an order that reflects how they perceive them. This order is often in terms of agreement, significance, importance and so on, depending on the focus of the particular research study (McKeown \& Thomas, 1988).

\section{Resources}

Participants sorted the thirty statements (Appendix 1) representing two dimensions of musical performance; the task-theory and the self-theory. Task-theory statements reflected participants' beliefs about what is important in producing and defining a successful performance, while self-theory statements reflected participants' beliefs about themselves as 
musicians. The statements that formed the concourse in this study were designed to reflect the dimensions of ability, effort, confidence, luck and chance, and significant others. Participants were asked to express the strength of their agreement on a -3 to +3 scale. It should be noted that the lower end of the scale was not an expression of disagreement; rather, statements placed at this point were less strongly agreed with than those higher on the scale. In common with other Q studies a forced distribution method was applied (Kerlinger, 1973), which avoids participants 'bunching' their agreement ratings and forces them to carefully compare and consider their response to each statement. The statements were presented using an online environment that replicated the features of a physical Q-sort. In a pilot phase, the concourse was trialled with several undergraduate music students to ensure language and presentation was clear and that the online environment was straightforward to navigate.

Data was also collected on five contextual variables. Participants were asked to self-report the genre of music they most frequently play in public, which was used to define their 'primary genre affiliation'. They chose from classical, Scottish traditional, jazz, or pop/ rock. It should be recognised that this approach did not reflect the extent to which participants engaged across the four genres. They were asked to provide information about their gender, age, the type of institution they were attending (university or conservatoire) and the number of years they had been learning their main instrument.

\section{Participants}

165 participants completed the study, drawn from four Scottish universities $(81 \%, n=134)$ and one Scottish conservatoire $(19 \%, n=31)$. Each of these institutions offered a four-year undergraduate honours degree programme in music ${ }^{1}$ which included a significant element of solo and ensemble performance. Following discussion with the course directors of these programmes, students on each degree were contacted by email and invited to complete the Qsort online. At the time the study was run, 165 students represented around $31 \%$ of the total population who were invited to participate. $61 \%$ of the sample was female $(n=100)$. By primary genre affiliation, $65 \%$ of the group described themselves as classical musicians $(n=108), 10 \%$ as Scottish traditional musicians $(n=15), 6 \%$ as jazz musicians $(n=10)$ and $19 \%$ as pop/ rock musicians $(n=32) .51 \%$ of the sample were aged between 18 and 20 years $(n=$ $85), 41 \%$ were between 21 and 25 years $(n=67), 4 \%$ were between 26 and 30 years $(n=7)$ and $4 \%$ were older than 30 years. $2 \%$ of the sample had been learning their main instrument for less than three years $(n=3), 6 \%$ had been studying between three and five years $(n=9)$, $23 \%$ between six and seven years $(n=38), 50 \%$ for between eight and ten years $(n=76)$ and $22 \%$ had been studying their main instrument for more than ten years $(n=36)$.

1 The Scottish Higher Education system is based on a four-year bachelors programme at honours level, rather than the English three-year duration of study. 


\section{Analysis}

Data analysis comprised three stages. In the first, the Q-sort data was correlated and subjected to centroid factor analysis. The aim of this analysis was to find a small number of 'typical' Qsorts that encapsulated the variety of the original dataset. Analysis suggested six factors with eigenvalues greater than 1.0 which indicated that that the variance between the original 165 sorting patterns could be reduced to six 'typical' sorting patterns. Each of these sorting patterns represents a statistically distinctive viewpoint on self and task-theories of musical performance. In the second stage, by examining the factor loadings it was possible to identify which of the six viewpoints best represented the views of each participant. As data on the participants' primary musical performance genre had been collected, it was possible to evaluate whether each viewpoint was more or less heavily populated with any particular musical genre. Finally, the predictive relationship between participant age, gender, years of playing, institution type and primary genre affiliation was examined.

\section{ReSULTS}

\section{Summary of 'typical' viewpoints}

The distinctive characteristics of the six 'typical' sorting patterns, or viewpoints, were of particular interest and were identified in two ways. First, within each viewpoint there were statements that were rated very high or low in terms of participant agreement. These statements elicited strongest feelings among those who associated with the viewpoint, both positive and negative. Second, there were statements that were rated significantly differently in the viewpoint when compared with the other viewpoints. This second set of distinguishing statements is accompanied in the following tables by a significance level, as these statements are those that statistically differentiate the viewpoints. Specific statements (summarised in Appendix 1) are referred to in parentheses (e.g. S3 refers to statement three). Where participants are described as 'loading most heavily' on a factor, this means that their sorting pattern was most closely related statistically to the viewpoint represented by that factor; this viewpoint is therefore the best reflection of their task and self-theories about musical performance.

\section{Viewpoint One - The 'Introverted, Hard-Working' Performer}

The first viewpoint, and the least popular among the participant group, was distinguished by task theories that stressed the importance of hard work, effort and concentration. Luck and chance were viewed as relatively unimportant. Statements relating to audience satisfaction and to the role of other musicians were rated significantly lower by participants who associated with this viewpoint, compared with those who did not.

$9.1 \%$ of the participant group loaded most heavily on factor one $(\mathrm{n}=15)$. Association by genre affiliation was jazz (10\%, ranked 3rd), classical (11.1\%, ranked 4th), Scottish traditional 
$(6.7 \%$, ranked 4 th) and pop/ rock (3.1\%, making this the least popular view among pop/ rock musicians). The typical Q-sort for this viewpoint is presented as Figure 1, and a summary table of its characteristic features in Table 1.

Insert Figure 1 about here

Insert Table 1 about here

\section{Viewpoint Two - The 'Positive' Performer}

This viewpoint placed great importance on 'being a performer' and on the role of other musicians in creating a successful performance. Participants who associated most strongly with this viewpoint appeared more robust at dealing with the effects of a poor performance.

$12.7 \%$ of the participant group loaded most heavily on factor two $(n=21)$, making this the second-least common viewpoint. Association by genre affiliation was $28.1 \%$ for rock/ pop musicians, making this the second-most popular view for that group. For the other genres, association was $10 \%$ for jazz (ranked third) and $6.7 \%$ for Scottish traditional (ranked fourth). It was the least popular viewpoint for classical musicians $(9.3 \%$ loading on the factor). The typical Q-sort for this viewpoint is presented as Figure 2, and a summary table of its characteristic features in Table 2.

Insert Figure 2 about here

Insert Table 2 about here

\section{Viewpoint Three - The 'Sensitive' Performer}

The statements that were prominent in this viewpoint often related to sensitivity to audience reaction and a view that a poor performance had a powerful effect on self-theory. Technical mastery was relatively low-rated by participants associated with this viewpoint in the context of both self and task-theory.

$14.5 \%$ of the participant group loaded most heavily on factor three $(n=24)$. Association by genre affiliation was Scottish traditional $(40 \%$, therefore the most popular viewpoint for traditional musicians), jazz (10\%, ranked 3rd), pop/ rock (18.8\%, ranked 3rd) and classical (10.2\%, ranked 5th). The typical Q-sort for this viewpoint is presented as Figure 3, and a summary table of its characteristic features in Table 3.

Insert Figure 3 about here

Insert Table 3 about here 


\section{Viewpoint Four - The 'Sensitive, Technical' Performer}

The fourth viewpoint was characterised by sensitivity to tutor input and to a poor performance. Technical control and confidence were important aspects of task-theory. 19.4\% of the participant group loaded most heavily on factor four $(n=32)$. Association by genre affiliation was jazz (40\%, making this the most popular viewpoint for jazz musicians), classical (23.1\%, therefore the second-most popular viewpoint for classical musicians), Scottish traditional $(6.7 \%$, ranked 4 th for this group) and pop/ rock (6.3\%, ranked 5 th). The typical Q-sort for this viewpoint is presented as Figure 4, and a summary table of its characteristic features in Table 4.

Insert Figure 4 about here

Insert Table 4 about here

\section{Viewpoint Five - The 'Outward Looking, Confident' Performer}

With $20 \%$ of the participant group loading most heavily on factor five $(n=33)$ this was the second most popular viewpoint. There was a focus on audience satisfaction and on confidence as a performer, and much less importance was attributed to the instrumental teacher or the role of assessment compared with other viewpoints.

Association on this factor by genre affiliation was pop/ rock (31.3\%, making this the most popular viewpoint for pop/ rock performers), Scottish traditional (26.7\%, ranked 2nd), jazz (30\%, ranked 2nd) and classical (14.5\%, ranked 3rd). The typical Q-sort for this viewpoint is presented as Figure 5, and a summary table of its characteristic features in Table 5.

Insert Figure 5 about here

Insert Table 5 about here

\section{Viewpoint Six - The 'Technical' Performer}

This viewpoint reflected a task-theory that saw technical competence and preparation as highly important. Participants felt that a poor performance had a significant impact on how they felt about themselves, and they reflected lower confidence levels as performers when compared to other groups. This was the most popular viewpoint, with $24.2 \%$ of the participant group loading most heavily on factor six $(n=40)$. An analysis of genre affiliation suggested that this was the most popular viewpoint for classical musicians $(31.5 \%$ loaded most heavily on factor six). It was far less popular with the other genre affiliations; loadings were Scottish traditional (13.3\%, ranked 4 th) and pop/ rock $(12.5 \%$, ranked 4 th) and jazz $(0 \%$, so the least popular viewpoint for jazz musicians).

The typical Q-sort for this factor is presented as Figure 6, and a summary table of its characteristic features in Table 6. 


\section{Insert Figure 6 about here}

Insert Table 6 about here.

\section{The relationship between viewpoint association and primary genre affiliation}

Identifying these six distinctive viewpoints on musical performance was the first part of the analysis. Each viewpoint characterised the task of musical performance and the theorisation of self within performance in different ways. While interesting in themselves, the aim was to not only identify viewpoints but also to explore whether student musicians with particular genre affiliations tended to exhibit particular attitudes and values towards (1) the activity of musical performance (task-theory) and (2) themselves as musicians (self-theory). In the following section the relationship between genre affiliation and viewpoint association is therefore discussed. It should be noted that the analysis was qualitative and interpretative in nature, based on a visual inspection of distribution by primary genre affiliation across the factor loadings presented in Table 7. Also, identification with the various viewpoints was spread across genre affiliation in most cases; the focus in this discussion is on larger rather than dominant loadings.

\section{Insert Table 7 about here.}

\section{Classical musicians}

Table 7 indicates that over $50 \%$ of participants who identified themselves as 'classical' musicians associated most strongly with viewpoints four (the 'sensitive, technical performer') and six (the 'technical performer'). Viewpoint six was much less popular with the other genre groups while viewpoint four was dominated by jazz musicians but much less popular for the others. The characteristic task-theories of both viewpoints were quite consistent, distinguishable by beliefs in the importance of effort, preparation and technical control in securing a successful performance and in determining whether a performance was successful or not. The self-theories within both viewpoints reflected a perceived importance of the instrumental teacher in influencing how they saw themselves as performers. Both viewpoints reflected self-theories in which there was a perceived lack of capacity to be confident during future performances.

\section{Jazz musicians}

The majority of participants who described themselves as primarily 'jazz' musicians associated most strongly with viewpoints four (the 'sensitive, technical performer') and five (the 'outward looking, confident performer'). The distribution in Table 7 suggests that the popularity of viewpoint four was shared with classical participants while viewpoint five was popular with pop/ rock and Scottish traditional musicians. Interestingly, some aspects of these viewpoints are quite contradictory in terms of their characterisation of both task and selftheory. For example, viewpoint four reflects a view that the instrumental teacher had a strong 
impact on self-theory, while in viewpoint five this was rated as being of less importance. For participants who loaded most strongly on viewpoint five, audience enjoyment was much more of a feature in determining success than for those who identified with other viewpoints. Similarly, this viewpoint reflected a greater emphasis on the contribution of other musicians to the success of a performance, which was not reflected in the views of the 'sensitive, technical performer'.

Some similarities were observed between the two viewpoints. In the context of task-theory there was a shared belief that a sense of confidence before and during a performance was a vital component in its success. In both viewpoints a successful performance was believed to have a significant impact on how participants approached subsequent performances.

\section{Scottish traditional musicians}

$66.7 \%$ of participants who identified themselves as Scottish traditional musicians were most closely associated with viewpoints three (the 'sensitive performer') and five (the 'outward looking, confident performer'). These musicians loaded much more heavily on the 'sensitive performer' viewpoint than did any of the other genre groups (Table 7). Viewpoint five (outward looking, confident) was also popular with a significant number of pop/ rock and jazz musicians, though it was less popular with classical musicians. The task-theories reflected in both viewpoints gave high importance to audience reaction, though viewpoint three gave less importance to technical mastery of the instrument. Viewpoint five emphasised the importance of the contributions of other musicians to a successful performance and the importance of confidence in promoting a successful performance.

The self-theories reflected in both viewpoints placed less importance on the input of the instrumental teacher. Viewpoint three also reflected perceptions of lower levels of technical ability. There was a high degree of sensitivity to the effects of both good and bad performances in viewpoint three which was also present in viewpoint five. Viewpoint three reflected an emphasis on comparison of self-capability to that of the peer group, while viewpoint five reflected a lower evaluation of the importance of formal evaluation on the shaping of self-theory as a musician. A smaller number of Scottish traditional musicians $(13.3 \%)$ loaded most heavily on viewpoint six, the 'technical performer'.

\section{Pop/ rock musicians}

$59.4 \%$ of participants who defined themselves as 'pop/ rock' musicians were most closely associated with viewpoints two (the 'positive performer') and five (the 'outward looking, confident performer'). From Table 7 it can be observed that musicians from the other genre groups were less likely to load heavily on the 'positive performer' viewpoint. However, jazz and Scottish traditional musicians shared with pop/ rock musicians a tendency to associate strongly with the 'outward looking, confident' viewpoint. 
In the context of task-theory both viewpoints emphasised the importance of other performers in creating a successful performance. Viewpoint two conceptualised a successful performance as being artistic and creative, and reflected a low agreement that technical competence was the most important factor in determining success. Viewpoint five placed significant importance on the audience enjoying a performance, and a strong belief that high levels of confidence before and during a performance were important.

In the context of self-theory, both viewpoints suggested that a successful performance had a high impact on how individuals view themselves as performers. Other features of viewpoint two were strong agreement that being a performer was the most important aspect of their identity as a musician and low agreement that a poor performance had a significant impact on how participants felt. Viewpoint five reflected lower importance given to the instrumental teacher, and high levels of personal confidence. Previous experiences of formal assessment were ranked of much less importance in shaping the performer's view of themselves.

\section{The relationship between age, gender, years of playing, primary genre affiliation and viewpoint}

With a small set of 'typical' viewpoints established and an interpretative analysis of the relationship between primary genre affiliation and viewpoint completed, the final part of the analytical process was to statistically investigate whether there was any predictive relationship between the various contextual variables for each participant and the viewpoint with which they most closely associated. Results from a regression analysis indicated that neither gender $\left(\mathrm{R}^{2}=.0001, \mathrm{~F}(1,163)=0.14, \mathrm{p}=0.71\right)$, primary genre affiliation $\left(\mathrm{R}^{2}=.015, \mathrm{~F}(3,161)=0.84\right.$, $\mathrm{p}=0.48)$, participant age $\left(\mathrm{R}^{2}=.019, \mathrm{~F}(3,161)=1.06, \mathrm{p}=0.37\right)$, years learning the instrument $\left(\mathrm{R}^{2}=.015, \mathrm{~F}(4,157)=0.59, \mathrm{p}=0.67\right)$ or type of institution attended $\left(\mathrm{R}^{2}=0.005\right), \mathrm{F}(1,163)=$ $0.81, \mathrm{p}=0.37$ ) explained variance in viewpoint association.

\section{DISCUSSION}

The purpose of this study was to investigate whether student musicians who identify in a performance context with one of four musical genres exhibit distinctive task and self-theories that relate to their primary genre affiliation. In the previous section the quantitative analysis of a Q-sort was reported, identifying six distinctive viewpoints. Following that analysis the relationship between how participants responded to the sorting process and their genre affiliation was explored in a qualitative manner. Finally, no significant relationship was found between participants' age, gender, primary genre affiliation, years of study or institution type and their viewpoint association. From these three analytical processes it was clear that, in most cases, genre affiliation was associated with a range of viewpoints, thus making it difficult to conclude that any one viewpoint represented the 'view' of a particular genre group. However, the qualitative analysis suggested that some interesting (though complex) features of participants' sorting patterns could be raised and that in some cases these could be related to primary genre affiliation. 
Concluding that no one viewpoint represented the perceptions of a particular genre group confirms the findings of Welch et al. (2008), and may reflect the complex reality of musical performance and the flexibility that is required of emerging professional musicians. It may be that the complexity identified in this study is in part related to the requirement that musicians be able to fit into a multitude of communities of practice, each with its own norms, and therefore any attempt to reduce this to a single 'view' is flawed. As Welch et al. comment, "the requirements for highly skilled musical performance can transcend particular group characteristics" (Welch, et al., 2008:203). On this basis, it may not be valid to refer to a 'community of practice' that relates to one musical genre, but rather to a multiplicity of communities across which the undergraduate music student learns to negotiate. Importantly, however, the evidence presented in this paper suggests at the very least that undergraduate music students understand themselves and the task of musical performance in profoundly different ways, and this reality (whether genre-based or not) has important implications for music education and pedagogy at an advanced level.

\section{Educational implications}

The primary impulse to conduct this piece of research came from a personal awareness of the challenges facing music educators working in the higher education sector, particularly those that relate to the expansion and diversity of provision over the past decade. I therefore wish to conclude this paper by raising two specific points that relate to pedagogy.

The first relates to the teaching of musical performance at university and conservatoire level. Traditionally, music within higher education has tended to focus on common practice repertoire stretching to serious twentieth-century music and earlier genres. However, as music in higher education becomes a more inclusive subject involving the performance of a range of musical genres, so it is important that the teaching of performance moves on to consider the implications for learning of the self and task-theories of students within this range of genres. Put another way, effective instrumental teaching is consonant with normative aspects of the musical genre being professed (Mills, 2002). If different genres elicit or demand different attitudes and priorities of musicians, it is clear that teaching must also embrace these for the performer to be successful, or feel comfortable, within that genre. So while classical musicians tend to place high importance on technique, for example, this emphasis may not be so important for rock/ pop musicians whose views (and whose community of practice) may be more concerned with audience response, or confidence, or other musicians. Within the teaching process it is vital that instrumental teachers ensure consistency between their chosen focus or priority for teaching and the perceived demands of the particular genre. 'Successful' performance is, from the evidence of the viewpoints reported earlier, constructed in different ways and these may relate to the genre being performed, therefore teaching for success should embrace these differences. Perhaps most importantly, teachers of musical performance should recognise that self-concept and task perception vary between their students and that large discrepancies between what the student thinks about the task and what they think about 
themselves may play a significant role in determining how 'successful' they actually are. On the basis of the previous analysis, instrumental teachers cannot simply assume that the self and task-theories they associated with a particular musical genre are either shared by, or agreed with on the part of, the individual student.

A second point relates to assessment. Assessment should be organised in such a way as to both accurately evaluate the quality of the student's performance and to provide helpful and formative feedback to the student (Burt \& Mills, 2006). If it is to fulfil both functions (rather than simply provide a grade), it will need to be carried out in a way that is sympathetic both to the genre performed and which appears to value the same things that the genre does (Hewitt, 2004). There are important questions here about the types of criteria used to assess widely varying genres of music, and about how the whole process of assessment is structured (Stanley, Brooker, \& Gilbert, 2002). Assessment in solo performance must recognise the value systems of the genres being performed, as well as those structural norms through which public performance is mediated (Daniel, 2004). Without this, it might be predicted that students will place little value on assessment other than as a means of deriving a grade. The grade, the process and the resulting feedback will not be recognised as having a valid role in shaping future work or development.

\section{Conclusion}

This study confirms the findings of other research, specifically that undergraduate music students cannot be assumed to have a particular viewpoint on musical performance that is a function of their primary genre affiliation. The results should, of course, be treated with appropriate caution. While participants were allocated a primary genre affiliation based on their response to a question about the genre of music they most frequently performed in public, this is not the only way that primary genre affiliation could be established. Indeed, frequency of performance may be influenced by a range of factors including financial reward. It would be useful, in future research, to include other approaches to establishing primary genre affiliation. Furthermore, asking participants to nominate one musical genre ignores the complexity of musical development. The participants in this study may perform several genres of music, and limiting the description of their engagement to a single genre affiliation risks losing the richness of that experience. Future research should take a more sophisticated approach to quantifying and describing participants' holistic musical experience. In terms of methodology, future research should also address the issue of sample size in this study, specifically the disparity between the classical musicians and other genre affiliations. Generalisations of the findings in this study may be compromised by the unequal sample sizes evident in all the dependent variables excepting gender (i.e. institution, primary genre affiliation, age, and years learning the instrument).

Finally, further research is needed to better understand the antecedents of the viewpoints described in this paper. It is important for educators to explore the significant influences and events that lead music students to develop the views on music performance articulated within 
the Q-sorts. In particular, it would be useful to explore the relationship between musical self and task-theories and those that students employ in other domains. Is the musical identify of student musicians particularly 'musical', or is it a function of more general psychological traits? 


\section{Bibliography}

Auslander, P. (2004). Performance analysis and popular music: a manifesto. Contemporary Theatre Review, 14(1), 1-13.

Brown, J. S., Collins, A., \& Duguid, P. (1989). Situated cognitions and the culture of learning. Educational Researcher, 18(1), 32-42.

Brown, S. R. (1980). Political subjectivity: Applications of $Q$ Methodology in political science. New Haven, CT: Yale University Press.

Burt, R., \& Mills, J. (2006). Taking the Plunge: The Hopes and Fears of Students as They Begin Music College. British Journal of Music Education, 23(01), 51-73.

Cope, P. (2002). Informal learning of musical instruments: the importance of social context. Music Education Research, 4(1), 93-104.

Creech, A., Papageorgi, I., Duffy, C., Morton, F., Hadden, E., Potter, J., et al. (2008). Investigating Musical Performance: Commonality and Diversity among Classical and Non-Classical Musicians. Music Education Research, 10(2), 215-234.

Cruz-Alcazar, P. P., Vidal-Ruiz, E., \& Perez-Cortes, J. C. (2003). Musical style identification using grammatical inference: the encoding problem progress in pattern recognition, speech and image analysis. Berlin: Springer.

Daniel, R. (2004). Peer assessment in musical performance: the development, trial and evaluation of a methodology for the Australian tertiary environment. British Journal of Music Education, 21(1), 89-110.

Dweck, C. S. (1999). Self-theories: their role in motivation, personality and development. Philadelphia: The Psychology Press.

Hargreaves, D., \& Marshall, N. A. (2003). Developing identities in music education. Music Education Research, 5(3), 263-273.

Hewitt, A. (2004). Students' Attributions Of Sources Of Influence On Self-Perception In Solo Performance In Music. Research Studies in Music Education, 22(1), 42-58.

Kerlinger, F. N. (1973). Foundations of behavioral research. New York: Holt, Rinehart and Winston.

Lave, J., \& Wenger, E. (1991). Situated learning: legitimate peripheral participation. Cambridge: Cambridge University Press.

LeBlanc, A., Jin, Y. C., Obert, M., \& Siivola, C. (1997). Effect of audience on music performance anxiety. Journal of Research in Music Education, 45, 480-496.

Little, T. D., Lopez, D. F., Oettingen, G., \& Baltes, P. B. (2001). A comparative-longitudinal study of action control beliefs and school performance: On the role of context. International Journal of Behavioral Development, 25, 237-245.

McKeown, B., \& Thomas, D. (1988). Q Methodology. Newbury Park: Sage Publications.

Meyer, L. B. (1989). Style and music: theory, history and ideology. Chicago: University of Chicago Press.

Mills, J. (2002). Conservatoire students' perceptions of the characteristics of effective instrumental and vocal tuition. Bulletin of the Council for Research in Music Education, 153-154, 78-82.

Schmitz, B., \& Skinner, E. A. (1993). Perceived control, effort, and academic performance: Interindividual, intraindividual, and multivariate time-series analysis. Journal of Personality and Social Psychology, 64, 1010-1028.

Skinner, E. A. (1995). Perceived control, motivation and coping. Thousand Oaks, CA: Sage Publications.

Stanley, M., Brooker, R., \& Gilbert, R. (2002). Examiner Perceptions of Using Criteria in Music Performance Assessment. Research Studies in Music Education, 18(1), 46-56.

Stephenson, W. (1953). The study of behavior: Q-technique and its methodology. Chicago: University of Chicago Press.

Stockfelt, O. (2004). Adequate modes of listening. In C. Cox \& D. Warner (Eds.), Audio Culture: Readings in Modern Music. London: Continuum.

Vygotsky, L. S. (1986). Thought and language. Cambridge, MA: The MIT Press.

Welch, G., Papageorgi, I., Haddon, L., Creech, A., Morton, F., de Bezenac, C., et al. (2008). Musical genre and gender as factors in higher education learning in music. Research Papers in Education, 23(2), 203-217. 


\section{Tables}

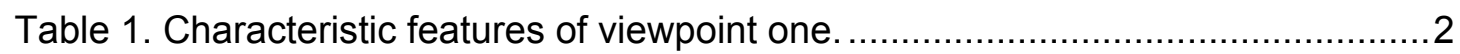

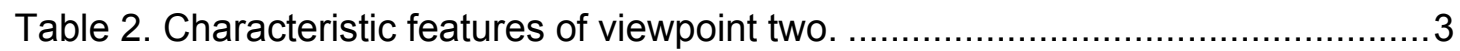

Table 3. Characteristic features of viewpoint three............................................ 4

Table 4. Characteristic features of viewpoint four........................................... 5

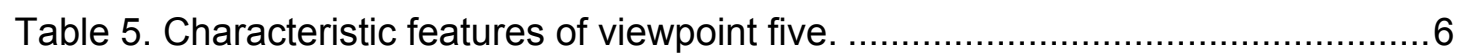

Table 6. Characteristic features of viewpoint six...............................................

Table 7. Association with the six viewpoints by primary genre affiliation................... 8 
Table 1. Characteristic features of viewpoint one.

\begin{tabular}{|c|c|c|}
\hline & Task-theory & Self-theory \\
\hline $\begin{array}{l}\text { Stronger } \\
\text { agreement }\end{array}$ & $\begin{array}{l}\text { - that hard work is required for } \\
\text { successful performance (S5, } \\
\mathrm{p}<.05 \text { ) } \\
\text { - that effort is required for } \\
\text { successful performance (S20, } \\
\mathrm{p}<.05 \text { ) } \\
\text { - that practice before the event is } \\
\text { important (S29) }\end{array}$ & $\begin{array}{l}\text { - no distinguishing features } \\
\text { compared to other factors }\end{array}$ \\
\hline $\begin{array}{l}\text { Weaker } \\
\text { agreement }\end{array}$ & $\begin{array}{l}\text { - that audience response is } \\
\text { significant in whether a } \\
\text { performance has been } \\
\text { successful or not }(\mathrm{S} 1, p<.01) \text {. } \\
\text { - that a successful performance } \\
\text { depends on other people }(\mathrm{S} 4, p \\
<.01) \text {. } \\
\text { - that luck and chance play little } \\
\text { role in determining the success } \\
\text { of a performance }(\mathrm{S} 7,23,27)\end{array}$ & $\begin{array}{l}\text { - no distinguishing features } \\
\text { compared to other factors }\end{array}$ \\
\hline
\end{tabular}


Table 2. Characteristic features of viewpoint two.

\begin{tabular}{|c|c|c|}
\hline & Task-theory & Self-theory \\
\hline $\begin{array}{l}\text { Stronger } \\
\text { agreement }\end{array}$ & $\begin{array}{l}\text { - that successful performances } \\
\text { depend on other people as } \\
\text { much as the individual (S4, } p< \\
.05 \text { ). } \\
\text { - that a successful performance } \\
\text { is characterised by artistic and } \\
\text { creative playing (S21). }\end{array}$ & $\begin{array}{l}\text { - that being a performer was the } \\
\text { most important aspect of their } \\
\text { identity as a musician (S10, } p< \\
.01) \\
\text { - that a successful performance } \\
\text { had a strong positive impact on } \\
\text { how they felt about themselves } \\
\text { as musicians (S3) }\end{array}$ \\
\hline $\begin{array}{l}\text { Weaker } \\
\text { agreement }\end{array}$ & $\begin{array}{l}\text { that to play well in public } \\
\text { requires complete technical } \\
\text { control of the instrument ( } 88 \text {, } \\
\mathrm{p}<.01 \text { ). } \\
\text { that technical competence is } \\
\text { the most important factor in } \\
\text { determining whether a } \\
\text { performance is successful or } \\
\text { not }\end{array}$ & $\begin{array}{l}\text { - that a poor performance has a } \\
\text { significant impact on how you } \\
\text { feel }(\mathrm{S} 6, \mathrm{p}<.01) \text {. }\end{array}$ \\
\hline
\end{tabular}


Table 3. Characteristic features of viewpoint three.

\begin{tabular}{|c|c|c|}
\hline & Task-theory & Self-theory \\
\hline Stronger agreement & $\begin{array}{l}\text { that audience reaction is } \\
\text { significant in determining } \\
\text { whether a performance has } \\
\text { been successful or not (S18, } \\
\mathrm{p}<.01 \text { ) }\end{array}$ & $\begin{array}{l}\text { - that a bad performance would } \\
\text { have a serious impact on their } \\
\text { approach to future } \\
\text { performances (S11, } p<.05 \\
\text { - that perceived success in a } \\
\text { performance had a highly } \\
\text { significant impact on how } \\
\text { they viewed themselves as } \\
\text { performers }(\mathrm{S} 6,3) \\
\text { - that personal ability is often } \\
\text { compared to that of their peer } \\
\text { group (S24) }\end{array}$ \\
\hline Weaker agreement & $\begin{array}{l}\text { - that technical mastery of the } \\
\text { instrument was important in } \\
\text { producing a successful } \\
\text { performance (S8, } p<.01) \\
\text { - that levels of confidence prior } \\
\text { to performing were important } \\
\text { in producing a successful } \\
\text { performance (S12) }\end{array}$ & $\begin{array}{l}\text { - that the instrumental teacher } \\
\text { is responsible for a successful } \\
\text { performance (S17, } p<.05) \\
\text { - that being a performer is the } \\
\text { most important aspect of } \\
\text { being a musician (S10). } \\
\text { - that they personally possessed } \\
\text { a high level of technical ability } \\
\text { on their instrument (S26). }\end{array}$ \\
\hline
\end{tabular}


Table 4. Characteristic features of viewpoint four.

\begin{tabular}{|c|c|c|}
\hline & Task-theory & Self-theory \\
\hline Stronger agreement & $\begin{array}{l}\text { that technical control of the } \\
\text { instrument is an important } \\
\text { factor in performing } \\
\text { successfully (S8 } p<.05) \\
\text { - that a high level of confidence } \\
\text { before a performance is an } \\
\text { important predictor of success } \\
\text { during the performance (S12, } \\
p<.01)\end{array}$ & $\begin{array}{l}\text { - that a poor performance has a } \\
\text { powerful effect on subsequent } \\
\text { confidence (S11, } p<.05) \\
\text { - that the instrumental teacher } \\
\text { has a significant impact on } \\
\text { how they view themselves as } \\
\text { performers (S2) } \\
\text { - that a good performance has a } \\
\text { positive impact on self- } \\
\text { perception as a performer (S3) } \\
\text { that a bad performance has a } \\
\text { significant negative impact on } \\
\text { their self-perception (S6) }\end{array}$ \\
\hline Weaker agreement & $\begin{array}{l}\text { - that artistic and creative } \\
\text { performing were important in } \\
\text { creating a 'successful' } \\
\text { performance (S21, } p<.01) \\
\text { - that concentration and effort } \\
\text { during a performance are } \\
\text { significant determinants in } \\
\text { success (S20, } p<.01) \\
\text { - that hard work and effort } \\
\text { prior to performing are } \\
\text { significant determinants in } \\
\text { success (S29, } p<.01) \\
\text { - that luck and chance are } \\
\text { significant in determining } \\
\text { whether a performance is } \\
\text { successful or not }(\mathrm{S} 23,27)\end{array}$ & $\begin{array}{l}\text { - that they have the capacity to } \\
\text { be successful in future } \\
\text { performances }(\mathrm{S} 30, p<.01)\end{array}$ \\
\hline
\end{tabular}


Table 5. Characteristic features of viewpoint five.

\begin{tabular}{|c|c|c|}
\hline & Task-theory & Self-theory \\
\hline $\begin{array}{l}\text { Stronger } \\
\text { agreement }\end{array}$ & $\begin{array}{l}\text { - that audience enjoyment is an } \\
\text { important aspect of successful } \\
\text { performance (S1, } p<.01 \text { ) } \\
\text { - that the contributions of other } \\
\text { musicians are crucial to a } \\
\text { successful performance (S4, } p< \\
.01 \text { ) } \\
\text { - that high levels of confidence } \\
\text { before (S12, } p<.01 \text { ) and during } \\
\text { (S16, } p<.01 \text { ) a performance } \\
\text { were more likely to lead to } \\
\text { success }\end{array}$ & $\begin{array}{l}\text { - that successful performance } \\
\text { had a high impact on how } \\
\text { individuals view themselves as } \\
\text { performers (S3) } \\
\text { - that they possess high levels of } \\
\text { confidence in personal ability } \\
\text { to be successful in any future } \\
\text { public performance (S30) }\end{array}$ \\
\hline $\begin{array}{l}\text { Weaker } \\
\text { agreement }\end{array}$ & $\begin{array}{l}\text { - that luck and chance influence } \\
\text { the success of a performance } \\
(\mathrm{S} 7,27) \text {. }\end{array}$ & $\begin{array}{l}\text { - that the instrumental teacher } \\
\text { has influence on how they } \\
\text { view themselves as performers } \\
(\mathrm{S} 2, p<.01) \\
\text { - that their instrumental teacher } \\
\text { has influence on their success } \\
\text { during performances (S17, } p<\text {. } \\
\text { 05) } \\
\text { - that previous experiences of } \\
\text { formal assessment were of } \\
\text { importance in shaping the } \\
\text { performer's view of themselves } \\
\text { (S15, } p<.01) \\
\text { that they had the capacity to be } \\
\text { lucky during a future } \\
\text { performance (S23) }\end{array}$ \\
\hline
\end{tabular}


Table 6. Characteristic features of viewpoint six.

\begin{tabular}{|c|c|c|}
\hline & Task-theory & Self-theory \\
\hline Stronger agreement & $\begin{array}{l}\text { - that hard work and preparation } \\
\text { are important for a successful } \\
\text { performance (S14) } \\
\text { - that technical instrumental } \\
\text { competence predicts a } \\
\text { performance's success (S28, } p< \\
.01) \\
\text { - that technical accomplishment in } \\
\text { performance can be used to } \\
\text { determine a performance's success } \\
\text { (S25, } p<.01)\end{array}$ & $\begin{array}{l}\text { that the instrumental } \\
\text { teacher has a significant } \\
\text { influence on self } \\
\text { perception as a musician } \\
\text { (S2) }\end{array}$ \\
\hline Weaker agreement & $\begin{array}{l}\text { - that luck and chance play an } \\
\text { important role in determining a } \\
\text { successful performance (S7) }\end{array}$ & $\begin{array}{l}\text { - that they had the capacity } \\
\text { to be lucky (S23) and that } \\
\text { being a performer was the } \\
\text { most important thing to } \\
\text { them as a musician (S10) } \\
\text { - that an unsuccessful } \\
\text { performance would lead } \\
\text { you to question your } \\
\text { ability as a performer (S6, } \\
p<.05 \text { ) } \\
\text { that they possessed the } \\
\text { capacity to enter a future } \\
\text { performance with a high } \\
\text { level of confidence (S30, } p \\
<.01 \text { ) }\end{array}$ \\
\hline
\end{tabular}


Table 7. Association with the six viewpoints by primary genre affiliation

\begin{tabular}{|l|l|l|l|l|l|l|}
\hline & $\begin{array}{l}\text { Viewpoint } \\
\text { One }\end{array}$ & $\begin{array}{l}\text { Viewpoint } \\
\text { Two }\end{array}$ & $\begin{array}{l}\text { Viewpoint } \\
\text { Three }\end{array}$ & $\begin{array}{l}\text { Viewpoint } \\
\text { Four }\end{array}$ & $\begin{array}{l}\text { Viewpoint } \\
\text { Five }\end{array}$ & $\begin{array}{l}\text { Viewpoint } \\
\text { Six }\end{array}$ \\
\hline Classical & $11.1 \%\left(4^{\text {th }}\right)$ & $9.3 \%\left(6^{\text {th }}\right)$ & $10.2 \%\left(5^{\text {th }}\right)$ & $\left.\mathbf{2 3 . 1} \% \mathbf{( 2}^{\text {nd }}\right)$ & $14.8 \%\left(3^{\text {rd }}\right)$ & $\mathbf{3 1 . 5} \%\left(\mathbf{1}^{\text {st }}\right)$ \\
\hline Jazz & $10 \%\left(3^{\text {rd }}\right)$ & $10 \%\left(3^{\text {rd }}\right)$ & $10 \%\left(3^{\text {rd }}\right)$ & $\mathbf{4 0} \%\left(\mathbf{1}^{\text {st }}\right)$ & $\mathbf{3 0} \%\left(\mathbf{2}^{\text {nd }}\right)$ & $0 \%\left(6^{\text {th }}\right)$ \\
\hline $\begin{array}{l}\text { Scottish } \\
\text { traditional }\end{array}$ & $6.7 \%\left(4^{\text {th }}\right)$ & $6.7 \%\left(4^{\text {th }}\right)$ & $\mathbf{4 0} \%\left(\mathbf{1}^{\text {st }}\right)$ & $6.7 \%\left(4^{\text {th }}\right)$ & $\mathbf{2 6 . 7} \%\left(\mathbf{2}^{\text {nd }}\right)$ & $13.3 \%\left(3^{\text {rd }}\right)$ \\
\hline Pop/ rock & $3.1 \%\left(6^{\text {th }}\right)$ & $\mathbf{2 8 . 1} \%\left(\mathbf{2}^{\text {nd }}\right)$ & $18.8 \%\left(3^{\text {rd }}\right)$ & $6.3 \%\left(5^{\text {th }}\right)$ & $31.3 \%\left(\mathbf{1}^{\text {st }}\right)$ & $12.5 \%\left(4^{\text {th }}\right)$ \\
\hline
\end{tabular}


2 Figures

Figure 1. Typical statement sort for viewpoint one .......................................... 10

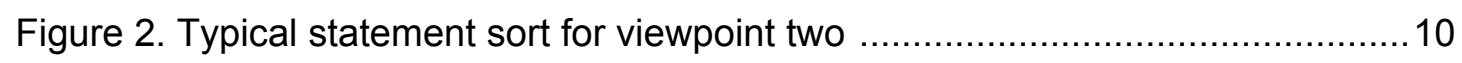

Figure 3. Typical statement sort for viewpoint three .......................................... 10

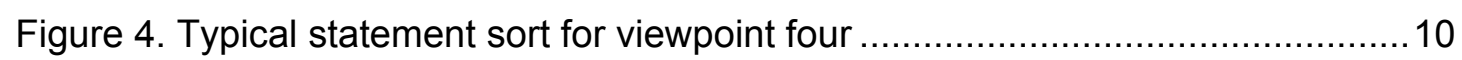

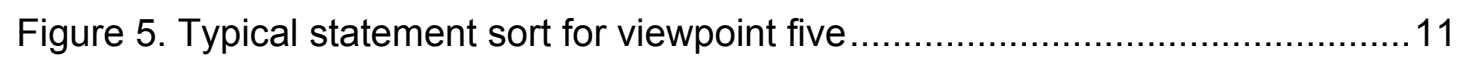

Figure 6. Typical statement sort for viewpoint six ........................................... 11 


\begin{tabular}{|c|c|c|c|c|c|c|}
\hline $\mathbf{- 3}$ & $\mathbf{- 2}$ & $\mathbf{- 1}$ & $\mathbf{0}$ & $\mathbf{1}$ & $\mathbf{2}$ & $\mathbf{3}$ \\
\hline 7 & $\mathbf{1} \boldsymbol{*}$ & 6 & 2 & 3 & 14 & $\mathbf{5}$ \\
\hline 23 & $\mathbf{4} \boldsymbol{\star}$ & $\mathbf{1 2 * \boldsymbol { * }}$ & 10 & 8 & 21 & $\mathbf{2 0 *}$ \\
\hline 27 & 18 & 13 & $\mathbf{1 1 * \boldsymbol { * }}$ & 9 & 22 & 29 \\
\hline & 28 & 15 & 16 & 19 & 30 & \\
\hline & & 25 & 17 & 24 & & \\
\hline & & 26 & & & \\
\hline
\end{tabular}

Figure 1. Typical statement sort for viewpoint one $\left({ }^{*}=p<.05,{ }^{* *}=p<.01\right)$

\begin{tabular}{|c|c|c|c|c|c|c|}
\hline $\mathbf{- 3}$ & $\mathbf{- 2}$ & $\mathbf{- 1}$ & $\mathbf{0}$ & $\mathbf{1}$ & $\mathbf{2}$ & $\mathbf{3}$ \\
\hline $\mathbf{6 * \boldsymbol { * }}$ & 7 & 15 & $\mathbf{2}$ & $\mathbf{4}$ & 1 & $\mathbf{1 0 *}$ \\
\hline $\mathbf{8 * \boldsymbol { * }}$ & 12 & 11 & $\mathbf{1 4} \boldsymbol{*}$ & 5 & 9 & 21 \\
\hline 28 & 25 & 13 & 16 & 17 & 20 & 3 \\
\hline & 27 & 19 & 22 & 18 & 24 & \\
\hline & & 23 & 26 & 29 & & \\
\hline & & & $\mathbf{3 0 *}$ & & & \\
\hline
\end{tabular}

Figure 2. Typical statement sort for viewpoint two $\left(^{*}=p<.05,{ }^{* *}=p<.01\right)$

\begin{tabular}{|c|c|c|c|c|c|c|}
\hline $\mathbf{- 3}$ & $\mathbf{- 2}$ & $\mathbf{- 1}$ & $\mathbf{0}$ & $\mathbf{1}$ & $\mathbf{2}$ & $\mathbf{3}$ \\
\hline 10 & 7 & $\mathbf{8 *}$ & 2 & 1 & $\mathbf{1 1 *}$ & 3 \\
\hline 12 & $\mathbf{1 7}$ & 13 & $\mathbf{5 *}$ & 4 & 14 & 6 \\
\hline 26 & 23 & 19 & 9 & 16 & 21 & 24 \\
\hline & 28 & 25 & 15 & 20 & 29 & \\
\hline & & 27 & $\mathbf{1 8 *}$ & 22 & & \\
\hline & & & $\mathbf{3 0 *}$ & & & \\
\hline
\end{tabular}

Figure 3. Typical statement sort for viewpoint three $\left({ }^{*}=p<.05,{ }^{* *}=p<.01\right)$

\begin{tabular}{|c|c|c|c|c|c|c|}
\hline-3 & -2 & -1 & 0 & 1 & 2 & 3 \\
\hline 23 & 7 & $18 * \star$ & 4 * & $1 \star \star$ & $8 *$ & 2 \\
\hline 27 & 22 & $20 * \star$ & 10 & $11 *$ & 9 & 3 \\
\hline \multirow[t]{4}{*}{$30 * \star$} & 26 & $24 \star \star$ & $15 *$ & $12 \star \star$ & 14 & 6 \\
\hline & 28 & 25 & 16 & 13 & 5 & \\
\hline & & $29 \star \star \star$ & 17 & 19 & & \\
\hline & & & 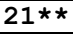 & & & \\
\hline
\end{tabular}

Figure 4. Typical statement sort for viewpoint four $\left({ }^{*}=p<.05,{ }^{* *}=p<.01\right)$ 


\begin{tabular}{|c|c|c|c|c|c|c|}
\hline-3 & -2 & -1 & 0 & 1 & 2 & 3 \\
\hline 7 & $2 \star \star *$ & $9 * \star$ & 6 & 5 & $12 \star \star$ & $1 \star \star$ \\
\hline $17 *$ & $15 * \star$ & 11 & 8* & 10 & $16 \star \star \star$ & 3 \\
\hline \multirow[t]{4}{*}{23} & 22 & 24 & 13 & 20 & 18 & $4 \star \star *$ \\
\hline & 27 & 25 & 14 * & $21 *$ & 30 & \\
\hline & & 28 & 19 & 29 & & \\
\hline & & & 26 & & & \\
\hline
\end{tabular}

Figure 5. Typical statement sort for viewpoint five $\left(^{*}=p<.05,{ }^{* *}=p<.01\right)$

\begin{tabular}{|c|c|c|c|c|c|c|}
\hline $\mathbf{- 3}$ & $\mathbf{- 2}$ & $\mathbf{- 1}$ & $\mathbf{0}$ & $\mathbf{1}$ & $\mathbf{2}$ & $\mathbf{3}$ \\
\hline 7 & 11 & $\mathbf{6}$ & 4 & 1 & 3 & 2 \\
\hline 10 & 12 & 13 & 16 & 5 & 9 & 14 \\
\hline 23 & 18 & 15 & 17 & 8 & 20 & 29 \\
\hline & 27 & 26 & 22 & 19 & 21 & \\
\hline & & $\mathbf{3 0 *}$ & 24 & $\mathbf{2 8 * \boldsymbol { * }}$ & & \\
\hline & & & $\mathbf{2 5 * \boldsymbol { * }}$ & & & \\
\hline
\end{tabular}

Figure 6. Typical statement sort for viewpoint $\operatorname{six}\left({ }^{*}=p<.05,{ }^{* *}=p<.01\right)$ 


\section{Appendix 1}

List of statements sorted by participants.

\begin{tabular}{|c|c|c|}
\hline Statement & Number & $\begin{array}{l}\text { Task }(T) \text { or Self }(S) \\
\text { theory }\end{array}$ \\
\hline $\begin{array}{l}\text { A 'successful' performance is one in which the audience goes } \\
\text { away happy. }\end{array}$ & 1 & $\mathrm{~T}$ \\
\hline $\begin{array}{l}\text { My instrumental teacher/s have had a highly significant impact } \\
\text { on how I see myself as a performer. }\end{array}$ & 2 & $S$ \\
\hline $\begin{array}{l}\text { If I have a successful performance, it makes me think of myself } \\
\text { in highly positive terms as a performer. It makes a significant } \\
\text { difference to how I think and feel. }\end{array}$ & 3 & $S$ \\
\hline $\begin{array}{l}\text { A successful performance depends as much on other people as } \\
\text { it does on you. }\end{array}$ & 4 & $\mathrm{~T}$ \\
\hline $\begin{array}{l}\text { If I was to be involved in a public performance in the near } \\
\text { future, I am sure I would have put in (or be able to put in) } \\
\text { sufficient effort and hard work to be successful. }\end{array}$ & 5 & $S$ \\
\hline $\begin{array}{l}\text { An unsuccessful performance usually leads you to question } \\
\text { your ability as a performer. }\end{array}$ & 6 & $S$ \\
\hline $\begin{array}{l}\text { Luck plays an important role in determining the success of my } \\
\text { performances. }\end{array}$ & 7 & $\mathrm{~T}$ \\
\hline $\begin{array}{l}\text { To play well in public you must be in complete technical } \\
\text { control of your instrument. }\end{array}$ & 8 & $\mathrm{~T}$ \\
\hline $\begin{array}{l}\text { I take my instrumental teacher's views about my playing very } \\
\text { seriously. }\end{array}$ & 9 & $S$ \\
\hline $\begin{array}{l}\text { Being a performer is the most important thing for me as a } \\
\text { musician. }\end{array}$ & 10 & $S$ \\
\hline $\begin{array}{l}\text { A previous bad performance seriously influences } \\
\text { confidence as I approach the next one. }\end{array}$ & 11 & $S$ \\
\hline $\begin{array}{l}\text { Performers who have high levels of confidence before } \\
\text { performing will be the most successful when performing. }\end{array}$ & 12 & $\mathrm{~T}$ \\
\hline $\begin{array}{l}\text { Success in a concert or gig depends on how confident you are } \\
\text { before you begin to perform. }\end{array}$ & 13 & $\mathrm{~T}$ \\
\hline $\begin{array}{l}\text { A successful public performance demands a high level of } \\
\text { preparation. }\end{array}$ & 14 & $\mathrm{~T}$ \\
\hline $\begin{array}{l}\text { My experiences of formal assessments or evaluations on my } \\
\text { instrument have been very important in shaping my confidence } \\
\text { in my abilities as a performer. }\end{array}$ & 15 & $S$ \\
\hline $\begin{array}{l}\text { Success in a concert or gig depends on how confident you feel } \\
\text { during the performance. }\end{array}$ & 16 & $\mathrm{~T}$ \\
\hline $\begin{array}{l}\text { I would attribute the level of success I achieve in a performance } \\
\text { to the teaching I have received from my instrumental teacher or } \\
\text { teachers. }\end{array}$ & 17 & $S$ \\
\hline $\begin{array}{l}\text { The audience have an important role in determining how } \\
\text { successful, or unsuccessful, a performance is. }\end{array}$ & 18 & $\mathrm{~T}$ \\
\hline $\begin{array}{l}\text { Success in a concert or gig depends upon how well you have } \\
\text { mastered the technical aspects of the music you will perform. }\end{array}$ & 19 & $\mathrm{~T}$ \\
\hline $\begin{array}{l}\text { Successful performance demands a high level of concentration } \\
\text { and effort during the performance itself. }\end{array}$ & 20 & $\mathrm{~T}$ \\
\hline $\begin{array}{l}\text { A 'successful' performance is one in which I manage to perform } \\
\text { in an artistic and creative way. }\end{array}$ & 21 & $\mathrm{~T}$ \\
\hline
\end{tabular}




\begin{tabular}{|l|c|c|}
\hline $\begin{array}{l}\text { My memories of previous performances are very significant in } \\
\text { determining how I feel now about public performance. }\end{array}$ & 22 & S \\
\hline $\begin{array}{l}\text { I think I can depend on a degree of luck during my next public } \\
\text { performance. Chance events will probably go in my favour. }\end{array}$ & 23 & S \\
\hline $\begin{array}{l}\text { I find myself comparing myself to other performers of my own } \\
\text { age and using them as a benchmark to evaluate my own } \\
\text { playing. }\end{array}$ & 24 & S \\
\hline $\begin{array}{l}\text { A 'successful' performance is one in which I have managed to } \\
\text { play with a high degree of technical accuracy. }\end{array}$ & 25 & T \\
\hline $\begin{array}{l}\text { If I was to be involved in a performance in the near future, I } \\
\text { would enter it thinking I have a high level of technical ability } \\
\text { on my instrument. }\end{array}$ & 26 & S \\
\hline $\begin{array}{l}\text { In my experience, chance events are usually a very important } \\
\text { factor in determining the success or failure of a public } \\
\text { performance. }\end{array}$ & 27 & S \\
\hline $\begin{array}{l}\text { Technical competence on your instrument is the most } \\
\text { important factor in determining whether you play successfully } \\
\text { in public. }\end{array}$ & 28 & T \\
\hline $\begin{array}{l}\text { To perform successfully in a concert or gig, it is important you } \\
\text { have worked hard on the repertoire or set you will play. }\end{array}$ & 29 & T \\
\hline $\begin{array}{l}\text { If I was to be involved in a public performance in the near } \\
\text { future, I think I would have a high level of confidence in my } \\
\text { ability to be successful. }\end{array}$ & 30 & S \\
\hline
\end{tabular}

